\title{
Comparative efficacy of newer insecticides against brown planthopper, Nilaparvata lugens Stal.
}

\author{
RANDEEP KR KUSHWAHA*, VIJAY KR KOSHTA AND SANJAY SHARMA
}

Department of Entomology, Indira Gandhi Agriculture University, RAIPUR (C.G.) INDIA

\section{ARITCLE INFO}

Received : 24.09 .2015

Revised : 07.02 .2016

Accepted : 21.02.2016

\section{KEY WORDS :}

$\mathrm{BPH}$, Nilaparvata lugens, Comparative bioefficacy of newer insecticides, Insecticides evaluation
*Corresponding author:

Email: rndp2010@gmail.com

\begin{abstract}
Comparative bioefficacy of few newer insecticides were tested against brown planthopper of rice under greenhouse conditions, IGKV, Raipur during 2013 and 2014. The mean of cumulative mortality during first year clearly indicated that all the insecticidal treatments were significantly superior over untreated control within ten DAT. The highest cumulative mortality (100.00\%) of BPH was observed in bifenthrin $10 \mathrm{EC}$ and chlorpyriphos $50 \mathrm{EC}+$ cypermethrin $5 \mathrm{EC}$. It was followed by fipronil of $(98.00 \%)$ and minimum $(44.00 \%)$ in indoxacarb $14.5 \mathrm{SC}$ whereas, during second year, all the insecticidal treatments were also significantly superior over untreated control within ten DAT and similar trend of the maximum cumulative mortality of BPH was noticed in bifenthrin 10 EC and chlorpyriphos $50 \mathrm{EC}+$ cypermethrin $5 \mathrm{EC}$ followed by fipronil of $(96.00 \%)$ with the minimum $(50.00 \%)$ in indoxacarb $14.5 \mathrm{SC}$. On the basis of overall compared the efficacy of different tested insecticides against BPH population of two years mean, revealed bifenthrin $10 \mathrm{EC}$ chlorpyriphos $50 \mathrm{EC}+$ cypermethrin $5 \mathrm{EC}$ to be highly effective (100.00\%) with quick knock down effect in controlling BPH whereas, fipronil $5 \mathrm{SC}$ and monocrotophos $36 \mathrm{SL}$ were also effective but it tooks time for getting $(97.00 \%)$ and (77.00\%) control. Descending order of mortality of BPH was observed with different insecticidal treatments as bifenthrin $\left(\mathrm{T}_{4}\right)<$ chlorpyriphos + cypermethrin $\left(\mathrm{T}_{6}\right)<$ fipronil $\left(\mathrm{T}_{3}\right)<$ monocrotophos $\left(\mathrm{T}_{1}\right)<$ imidacloprid $\left(\mathrm{T}_{2}\right)<\operatorname{indoxacarb}\left(\mathrm{T}_{5}\right)$ on the basis of all the observations.
\end{abstract}

How to view point the article : Kushwaha, Randeep Kr, Koshta, Vijay Kr and Sharma, Sanjay (2016). Comparative efficacy of newer insecticides against brown planthopper, Nilaparvata lugens Stal.. Internat. J. Plant Protec., 9(1) : 40-46. 